\title{
Morphologic characteristics of nevi associated with melanoma: a clinical, dermatoscopic and histopathologic analysis
}

\author{
Temeida Alendar ${ }^{1}$, Harald Kittler ${ }^{1}$
}

1 Department of Dermatology, Medical University Vienna, Vienna, Austria

Key words: nevus, melanoma, dermatopathology, dermatoscopy

Citation: Alendar T, Kittler H. Morphologic characteristics of nevi associated with melanoma: a clinical, dermatoscopic and histopathologic analysis. Dermatol Pract Concept. 2018;8(2):104-108. DOI: https://doi.org/10.5826/dpc.0802a07

Received: January 8, 2018; Accepted: February 1, 2018; Published: April 30, 2018

Copyright: (92018 Alendar et al. This is an open-access article distributed under the terms of the Creative Commons Attribution License, which permits unrestricted use, distribution, and reproduction in any medium, provided the original author and source are credited.

Funding: None.

Competing interests: The authors have no conflicts of interest to disclose.

All authors have contributed significantly to this publication.

Corresponding author: Harald Kittler, MD, Department of Dermatology, Medical University Vienna, Waehringer Gürtel 18-20, 1090, Vienna, Austria. Tel: ++44.1.40400.77110. Email: harald.kittler@meduniwien.ac.at

\footnotetext{
ABSTRACT Background: The aim of this retrospective study was to determine the frequency of nevus-associated melanomas and to better characterize the preexisting nevus from a histopathologic, clinical and dermatoscopic point of view.

Methods: We reviewed the histopathologic slides of a consecutive series of 357 melanomas and corresponding clinical and dermatoscopic images, if available.

Results: We found that $31(8.7 \%)$ melanomas were associated with a preexisting nevus, $284(79.5 \%)$ melanomas developed de novo, and in $42(11.8 \%)$ a preexisting nevus could not be excluded, although the alternative explanation that the entire lesion represented a melanoma was also possible. The preexisting nevus was a "superficial" or "superficial and deep" congenital nevus in 27 cases $(87 \%)$ and a Clark nevus in 4 cases (13\%). Clinical or dermatoscopic images were available in $149(41.7 \%)$ cases. The preexisting nevus, if visible, looked inconspicuous clinically or dermatoscopically. The median invasion thickness of nevus-associated melanoma was not significantly different from "de novo" melanomas but the frequency of in situ melanomas was higher in the "de novo " group ( $40.1 \%$ versus $16.1 \%)$. Patients with melanoma in association with a nevus were significantly younger (mean age $=55$ years, SD: 16 years) than patients with "de novo" melanomas (mean age $=68$ years SD: 15 years, $p<0.001$ ). When controlled for age and invasion thickness overall, survival did not differ significantly between patients with nevus-associated melanomas and patients with de novo melanomas.

Conclusions: From a histomorphologic point of view, the majority of melanomas arise de novo. If melanomas develop in a preexisting nevus, they usually occur in association with a "superficial" or "superficial and deep" congenital nevus.
} 


\section{Introduction}

It is generally agreed that the majority of melanomas arise de novo [1-5]. Tsao et al stated that the risk of malignant transformation of any specific melanocytic nevus is low [5]. Some authors, however, believe that melanomas frequently develop in so called "dysplastic nevi" [6-8]. Kaddu et al, on the other hand, proposed that small, superficial congenital nevi might play an important role as precursor lesions of melanomas [3]. The classification of the type of associated nevus is difficult because of the lack of a generally accepted classification of nevi. It has also been reported that patients with a melanoma in association with a preexisting nevus are significantly younger than patients with de novo melanomas $[1,3]$. The purpose of this study was to determine the frequency of melanoma in association with a preexisting nevus and to characterize the clinical, histopathologic and dermatoscopic appearance of nevi that are associated with melanoma.

\section{Materials and Methods}

\section{General Characteristics}

We analyzed a series of 357 consecutive cases of histologically verified melanomas excised between January 1, 2005, and December 31, 2007, at the Department of Dermatology, University of Vienna Medical School. Clinical images were taken with a Nikon D300 12.3MP DSLR camera (Nikon Corp, Tokyo, Japan). Dermatoscopic images were acquired either with DermLite FOTOsystem (DermLite FOTO model combined with CanonG12 digital camera; 3Gen, San Juan Capistrano, CA, USA) or with a digital dermatoscopic imaging system MoleMax II ${ }^{\mathrm{TM}}$ (Derma Medical Systems, Vienna, Austria).

\section{Histopathologic Assessment and Review of Images}

All cases were subjected to standard histopathologic processing. Histopathologic slides were reviewed by the study authors and classified into the following subgroups: (1) de novo melanomas, (2) melanomas arising in a preexisting nevus, and (3) non-decidable cases. Histopathologic review of the case was performed without knowledge of the respective clinical or dermatoscopic images. We used standard histopathologic criteria to differentiate between melanomas and nevi. For the classification of associated nevi, we used the nevus classification according to Ackerman and differentiated between Clark nevi, superficial congenital nevi (Ackerman nevi), and "superficial and deep" congenital nevi (Zitelli nevi) [9]. A schematic presentation of the histopathologic characteristics of these nevi is given in Figure 1. The two study authors reviewed all available clinical and derma-

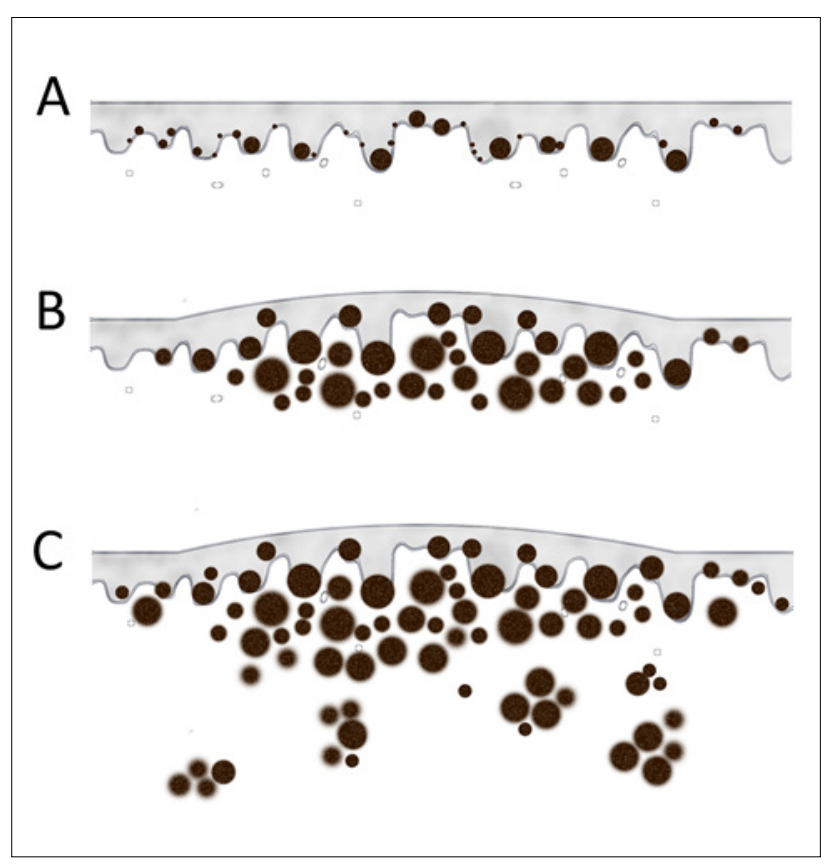

Figure 1. Schematic drawings of histomorphologic patterns of nevi. (A) Clark nevus; (B) Superficial congenital nevus; (C) Superficial or deep congenital nevus.

toscopic images on a computer screen without knowledge of the histopathologic diagnosis.

\section{Statistical Analysis}

Continuous data are given as mean and standard deviations (SD) or as median and range, as appropriate. T-tests or Mann-Whitney U tests were used to compare groups and the chi-square test for the comparison of proportions. The Kaplan-Meier method and a Cox proportional hazards analysis were used to analyze differences in overall survival. All given P-values are two-tailed. A P-value $<.05$ was considered statistically significant.

\section{Results}

\section{General Data}

We included 357 melanomas of 194 males (54.3\%) and 163 females $(45.7 \%)$. The mean age was 66.4 years (SD: 15.4). The majority of melanomas were located on the trunk ( $\mathrm{n}=118,33 \%), 137(38.4 \%)$ melanomas were in situ and $220(61.6 \%)$ were invasive. The median invasion thickness of all lesions was $0.94 \mathrm{~mm}$ (range $0.18-10 \mathrm{~mm}$ ). The general characteristics of the melanomas are given in Table 1. After reviewing the histopathologic slides, we found that 284 melanomas $(79.5 \%)$ developed de novo and 31 $(8.7 \%)$ in association with a preexisting nevus. In $42(11.8 \%)$ cases a preexisting nevus could not be excluded, although the alternative explanation that the entire lesion represented a melanoma was also possible. 
Differences Between de novo and Nevus-Associated Melanomas

The mean age of patients diagnosed with de novo melanomas was 68.2 years (SD: 14.8 years). Patients with a melanoma in association with a preexisting nevus were significantly younger with a mean age of 54.9 years (SD: 16.3 years, $\mathrm{p}<0.001)$. The frequency of in situ melanomas was significantly higher in the group of de novo melanomas $(40.1 \%, n=114)$ than in the group of melanomas in association with a preexisting nevus $(16.1 \%, \mathrm{n}=5, \mathrm{p}<0.001)$. The median tumor thickness of invasive melanomas in association with a preexisting nevus was $0.85 \mathrm{~mm}$ (range:0.3$7.0 \mathrm{~mm}$ ) and not significantly different from de novo melanomas $0.80 \mathrm{~mm}$ (range: $0.2-10.0 \mathrm{~mm}, \mathrm{p}=0.99$ ). Histomorphologically the associated nevus was a "superficial" or "superficial and deep" congenital nevus in 27 cases $(87 \%)$ and a Clark nevus in 4 cases $(13 \%)$. Nevus associated melanomas more frequently occurred on the trunk than de novo melanomas $(58.1 \%$ versus $27.4 \%, \mathrm{p}=0.004)$. The mean survival was 8.9 years (95\% CI: $8.6-9.4$ years) in the group of nevus-associated melanomas and 7.7 years 95\% CI: 7.38.0 years) in the group of de novo melanomas. Age (hazard ratio: 1.06, 95\% CI: $1.03-1.08, \mathrm{p}<0.001)$ and invasion thickness (hazard ratio: $1.37,95 \% \mathrm{CI}$ : 1.19-1.58, $\mathrm{p}<0.001$ ) were independent predictors of survival but not of whether the melanoma was nevus-associated or de novo (hazard ratio: 4.99 , 95\% CI: $0.67-37.23, p=0.12$ )

\section{Clinical and Dermatoscopic Morphology}

Clinical or dermatoscopic images were available in 17 cases of nevus-associated melanomas, and the preexisting nevus was visible clinically or dermatoscopically in 11 cases. The clinical images of 4 nevus-associated melanomas in Figure 2 show nevus remnants, mostly at the periphery of the lesion. In all 4 cases

TABLE 1. General characteristics of cases

\begin{tabular}{|c|c|c|c|}
\hline & $\begin{array}{c}\text { De novo } \\
\text { melanomas }\end{array}$ & $\begin{array}{c}\text { Nevus } \\
\text { associated } \\
\text { melanomas }\end{array}$ & Undecided \\
\hline $\mathrm{N}(\%)$ & $284(79.5 \%)$ & $31(8.7 \%)$ & $42(11.8 \%)$ \\
\hline Mean age (years) & 68.3 & 54.9 & 62.7 \\
\hline \multicolumn{4}{|l|}{ Gender } \\
\hline Male & $141(49.6 \%)$ & $20(64.5 \%)$ & $33(78.6 \%)$ \\
\hline Female & $143(50.4 \%)$ & $11(35.5 \%)$ & $9(21.4 \%)$ \\
\hline \multicolumn{4}{|l|}{ Anatomic Site } \\
\hline Head and Neck & $92(32.4 \%)$ & $4(12.9 \%)$ & $3(7.1 \%)$ \\
\hline Trunk & $78(27.5 \%)$ & $18(58.1 \%)$ & $22(52.4 \%)$ \\
\hline Upper extremities & $51(17.9 \%)$ & $5(16.1 \%)$ & $9(21.4 \%)$ \\
\hline Lower extremities & $63(22.2 \%)$ & $4(12.9 \%)$ & $8(19.1 \%)$ \\
\hline \multicolumn{4}{|c|}{ Histopathologic Criteria } \\
\hline $\begin{array}{l}\text { Median invasion } \\
\text { thickness ( } \mathrm{mm})\end{array}$ & 0.80 & 0.85 & 0.60 \\
\hline $\begin{array}{l}\text { In situ melanomas } \\
(n, \%)\end{array}$ & $114(40.1 \%)$ & $5(16.1 \%)$ & $19(45.2 \%)$ \\
\hline Ulceration $(n, \%)$ & $29(10.2 \%)$ & $2(6.5 \%)$ & $3(7.1 \%)$ \\
\hline
\end{tabular}

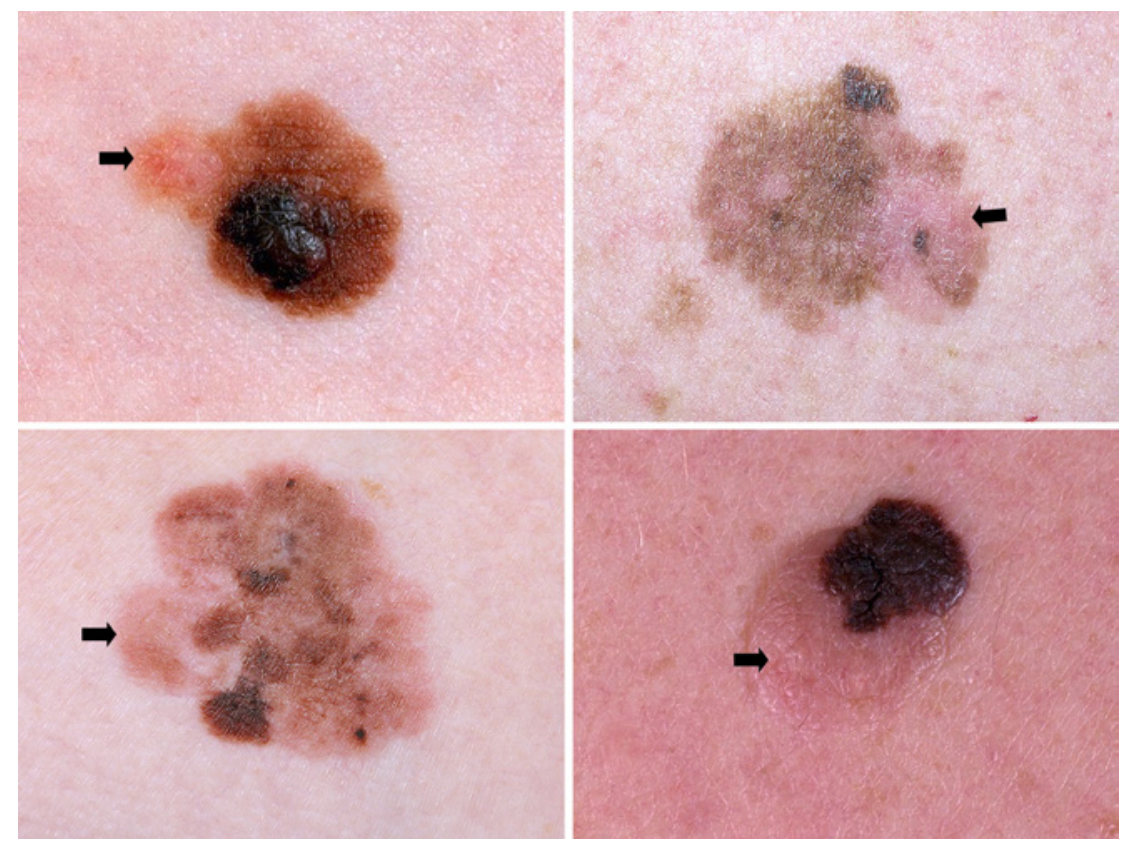

Figure 2. Clinical images of nevus-associated melanomas. [Copyright: @2018 Alendar et al.]

the nevus was of the congenital type. Dermatoscopic images were available in 5 nevus-associated melanomas. The clinical, dermatoscopic and histopathologic images of nevus-associated melanomas are shown in Figures 3 and 4. Figure 5 shows clinical and dermatoscopic images of 2 melanomas arising in a superficial and deep congenital nevus; one nevus has a pattern of clods and the other a reticular pattern.

\section{Discussion}

The results of our study support the view that most melanomas arise de novo. The proportion of nevus-associated melanomas in our study was smaller than $10 \%$ 
Figure 3. Clinical-dermatoscopic-pathologic correlation of a melanoma-associated nevus. [Copyright: @2018 Alendar et al.]

and thus lower than in most other studies on this topic [2]. The reason for this might be that we were very strict with regard to the applied histopathologic criteria to differentiate between melanocytes of a nevus and a melanoma. This resulted in a considerable proportion of cases in which we could not decide if there was an associated nevus or not. If these cases were to be added to the obvious nevus-associated melanomas, the proportion of nevus-associated melanomas in our study would be in the range of $20 \%$, which is similar to most other studies.

The concept of stepwise tumor progression from a common nevus over a "dysplastic nevus" to melanoma, as set forth by Clark and others, is not supported by our data [10]. We found that if melanomas develop in an associated nevus, it is most often a "superficial" or a "superficial and deep" congenital nevus. A Clark nevus is less often associated with a melanoma. Our findings do not support the concept that "melanocytic dysplasia," if it exists, has any predictive value with regard to the chance that a melanoma may arise in a specific nevus. Given the original description by Clark and coworkers, it has been proposed that the "dysplastic nevus" is a risk marker and a precursor of melanoma[11]. Recently the latter view has been questioned because clinical data have shown that it lacks legitimacy. The subject of the "dysplastic nevus" and its role as a precursor of melanoma is difficult to comprehend because what is usually termed "dysplastic nevus" is a heterogeneous group of melanocytic proliferations. According to Ackerman, what is termed "dysplastic nevi" consist of three

Figure 4. Clinical-dermatoscopic-pathologic correlation of a melanoma-associated nevus. [Copyright: (C2018 Alendar et al.]
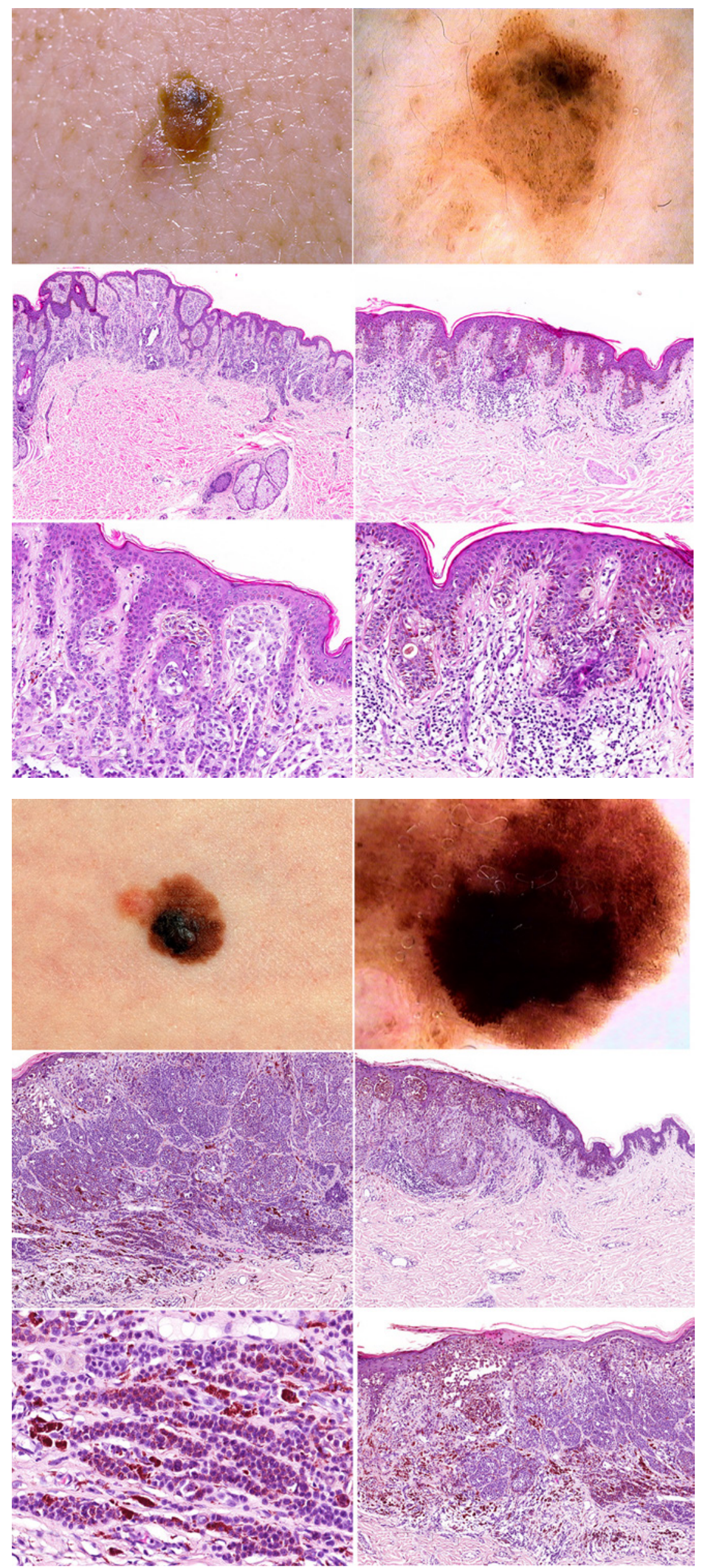


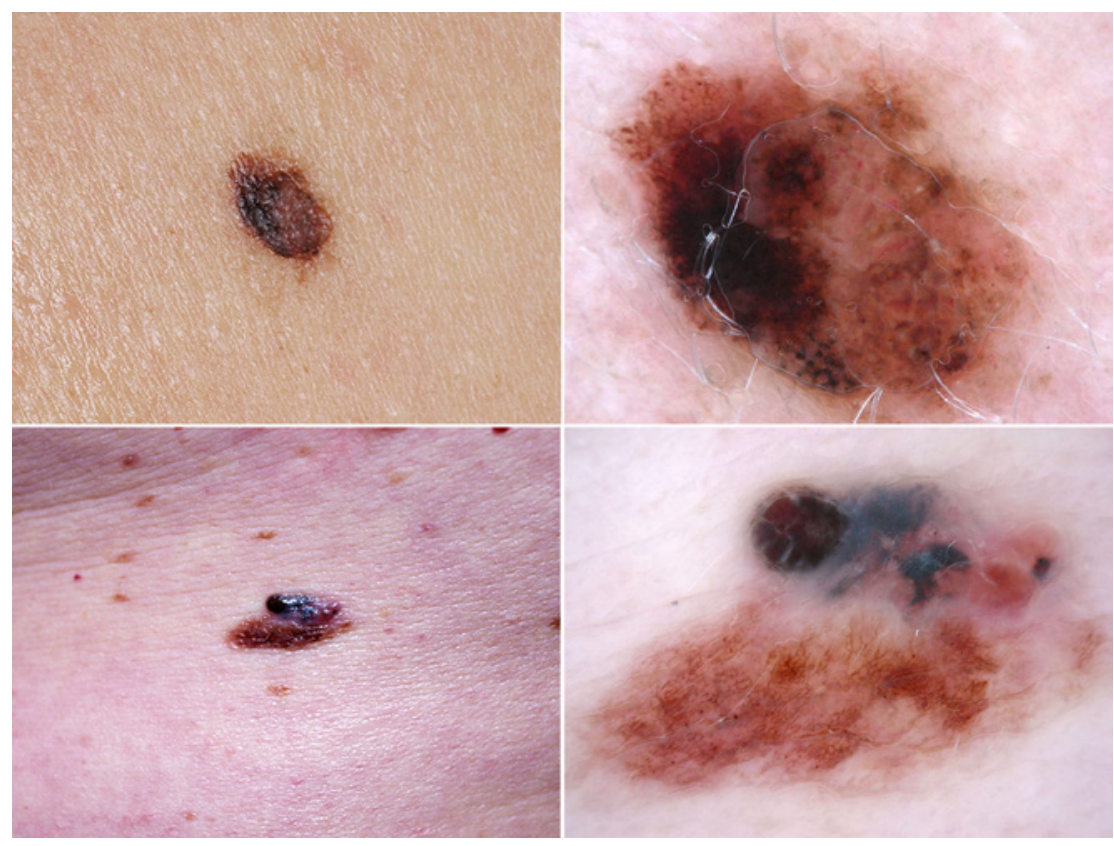

Figure 5. Clinical and dermatoscopic images of two nevus-associated melanomas. [Copyright: (C2018 Alendar et al.]

different types of nevi: (1) Clark nevi, (2) "superficial" congenital nevi, and (3) "superficial and deep" congenital nevi. Clark nevi are clinically flat and mainly junctional, although a few nests of melanocytes may be present in the papillary dermis. Dermatoscopically they usually show a reticular pattern. "Superficial" and "superficial and deep" congenital nevi usually have a junctional part but a more prominent dermal part. While melanocytes in a "superficial" congenital nevus are confined to the papillary dermis and the upper part of the reticular dermis they extend to the deep reticular dermis in a "superficial and deep" congenital nevus. Both nevi are usually raised clinically. Dermatoscopically they may show a pattern of clods, a reticular pattern, or a combination of both. If clinical and dermatoscopic images of these nevi were available in our series, they looked rather inconspicuous and not atypical or "dysplastic." Although our study shows that small congeni-

tal nevi are most commonly associated with melanoma, we do not think that this supports the view that they should be excised prophylactically to prevent melanoma. The risk of malignant transformation of a single nevus is so low that a general recommendation for prophylactic excision cannot be given. It is important to note, however, that we used the term "congenital" in a histopathologic sense. It does not mean that those nevi are present at birth. "Superficial" and "superficial and deep" congenital nevi usually appear in childhood or adolescence but share histomorphologic features (architecture, adnexocentricity) with large congenital nevi. To answer the question as to whether prophylactic excisions of small congenital nevi are worthwhile, we would need a prospective interventional study, but the low incidence of melanoma in comparison to the high number of nevi make it highly unlikely that such a prospective interventional trial will ever be conducted.

\section{References}

1. Bevona C, Goggins W, Quinn T, et al. Cutaneous melanomas associated with nevi. Arch Dermatol. 2003;139:1620-1624.

2. Pampena R, Kyrgidis A, Lallas A, Moscarella E, Argenziano G, Longo C. A meta-analysis of nevus-associated melanoma: Prevalence and practical implications. J Am Acad Dermatol. 2017 Nov;77(5):938-945.e4.

3. Kaddu S, Smolle J, Zenahlik P, et al. Melanoma with benign melanocytic naevus components: reappraisal of clinicopathological features and prognosis. Melanoma Res. 2002;12:271-278.

4. Banky J, Kelly JW, English DR, et al. Incidence of new and changed nevi and melanomas detected using baseline images and dermoscopy in patients at high risk for melanoma. Arch Dermatol. 2005;141:998-1006.

5. Tsao H, Bevona C, Goggins W, et al. The transformation rate of moles (melanocytic nevi) into cutaneous melanoma. Arch Dermatol. 2003;139:282-288.
6. Crowson AN, Magro CM, Sanchez-Carpintero I, Mihm MC Jr. The precursors of malignant melanoma. Recent Results Cancer Res. 2002;160:75-84.

7. Gruber SB, Barnhill RL, Stenn KS, et al. Nevomelanocytic proliferations in association with cutaneous malignant melanoma: a multivariate analysis. J Am Acad Dermatol. 1989;21:773.

8. Kanzler MH, Mraz-Gernhard S. Primary cutaneous malignant melanoma and its precursor lesions: diagnostic and therapeutic overview. J Am Acad Dermatol. 2001 Aug;45(2):260-276. melanocytic nevi. Common and dysplastic, normal and atypical, or Unna, Miescher, Spitz, and Clark? Am J Dermatopathol. 1992 Oct;14(5):447-453.

10. Miller AJ, Mihm MC Jr. Melanoma. N Engl J Med. 2006 Jul 6;355(1):51-65.

11. Clark WH Jr, Reimer RR, Greene M, Ainsworth AM, Mastrangelo MJ. Origin of familial malignant melanomas from heritable melanocytic lesions. 'The B-K molesyndrome'. Arch Dermatol. 1978 May;114(5):732-738.
9. Ackerman AB, Milde P. Naming acquired 